\title{
VARIA
}

\section{MINERVA Y LAS MUSAS EN EL HELICÓN: UNA NUEVA PINTURA DE MARTÍN DE VOS}

La visita de Minerva a las musas en el Helicón de Martín de Vos [Fig. 1] $]^{1}$ es pintura que añadir a la copiosa producción catalogada en la monografía del profesor Armin Zweiter ${ }^{2}$ y desconocida hasta ahora en el coleccionismo madrileño del siglo XIX a juzgar por el alcance de la memoria. Presumimos que su origen está en momentos de dominio español en los Países Bajos, y fluido contacto de importación de pinturas del Norte en los siglos XVI y XVII. Un coleccionismo de la nobleza española que desgraciadamente se ininterrumpe en el siglo XVIII y siguientes. Tampoco era conocido el asunto iconográfico que es producto del gusto por la antigüedad del renacimiento nórdico.

Los dobleces del lienzo y la acumulación de excrecencias no afectan a la prestancia cromática y valores sustanciales de la técnica. No advertimos repintes de especial consideración a simple vista, salvo en las juntas del empalme de los lienzos, ni otro tipo de intervencionismo, fuera de la superficie pictórica. Efectos del abandono y arranque del bastidor.

Es el estudio del estilo y la técnica de la pintura lo que avala su catalogación en la escuela de Amberes de fines del XVI y autoría a Martín de Vos en contacto con Italia. Esto es fácil de advertir en la ejecución y sentido cromático fundamentalmente. El viaje a Italia fue fundamental para cubrir sus anhelos de superación ${ }^{3}$. La tipología de los rostros femeninos y amplia frente, la transparencia de vida así como el colorido y equilibrada composición es típico del estilo. Es oportuna la obligada comparación con modelos similares en su producción. A título de ejemplo: en Rebeca y Eliezer de la colección Charles van Hove (1967) y Museo de Bellas Artes de Rouen ( $n^{\circ}$ S.R. 11), y Eliezer y Rebeca en Laban con el rostro de Minerva en segundo plano a la izquierda, la historia de Tobias, colección Ankacrona (1929) y La caida del Maná, colección dr. E. Schapiro, entre otros muchos ejemplos, y especialmente Apolo y las Musas del Museo Real de Bellas Artes de Bruselas ( $\mathrm{n}^{\circ}$ 3882), coincidiendo el asunto con el lienzo que nos ocupa. La riqueza del paisaje en la pintura que tratamos lo comparte Martín de Vos con igual generosidad en La caida del maná de la Pinacoteca de Munich ( $n^{\circ}$ 2672), el Bautismo de Cristo del tríptico de Santo Tomás, del Museo de Bellas Artes

\footnotetext{
${ }^{1}$ L. $145,5 \times 188,5$.

2 A. ZweITER, Marten de Vos als Maler, Ein Beitrag zur Geschichte der Antwerpener der Antwerpener der Antwerpener Malerei in der zweiten Hälfte des 16. Jahrhunderts, Berlín 1980.

${ }^{3}$ Leo van Puyvelde, La Peinture Flamante au siècle de Bosch et Breughel, París, 1962, p.384
} 
de Amberes ( $\mathrm{n}^{\circ}$ 77-81) con cruce de los troncos de los árboles y ramaje distribuido en horizontal, que repite en alegorías de animales como el ciervo, del Mittelrheinisches Landesmuseum de Mainz ( ${ }^{\circ}$ 667), y con igual sentimiento de la naturaleza en Jesús en el Tiberiades, Museo Nacional de Berlín (nº 709) y Triunfo de David (Kunsthaus am Museum, $\mathrm{n}^{\circ}$ 1355). El gusto por las ruinas y las arquitecturas es, igualmente obsesivo, en los fondos del Nacimiento de Jesús de la catedral de Amberes, y el rey de Silena del antiguo gremio de Ballesteros. Su gusto por los grupos compensados en primer plano, tenemos ocasión de verlo en la familia de la Virgen del Museo de Bellas Artes de Valenciennes ( $\mathrm{n}^{\circ}$ 253), como en Apolo y las ninfas citado. Los montículos rocosos centrados con espacios vacíos a los extremos de la composición están en Hércules (Londres, colección privada) y las figuras simétricas sentadas en la Alegoría de las artes liberales (colección privada en Bruselas).

La revisión de las obras conocidas de Martín de Vos nos permite probar su capacidad inventiva en las historias religiosas y mitológicas con composiciones irrepetibles. Esto hace difícil reconocer formas iguales en su producción, pero es notable el préstamo del colorido veneciano y la factura suelta y vibrante más rica que en sus colegas romanistas. La inventiva creadora fue reconocida por sus antiguos biógrafos ${ }^{4}$. La composición asume la monumentalidad y la armonía de la pintura italiana. Las musas se distribuyen en dos grupos enmarcando a Minerva que fija el eje de la composición con imponente majestad. Es la diosa de la sabiduría y de las artes con clara influencia en la escultura antigua. Destaca en un segundo plano próximo, frontal al espectador, junto a las musas que mueven sus brazos acorde al ritmo de los instrumentos musicales y las partituras. Todo en torno a la diosa mayestática en su visita al Helicón. En lo alto vuela Pegaso que rompe con una coz la roca donde mana el torrente de agua cristalina. De este monte abrupto brotan anémicos arbustos y plantas entre las grietas de la roca. Es un montículo típico recurso manierista, espíritu que inspira la atractiva escenografía del lienzo.

Es un ambicioso esquema decorativo, que se salva del rigor convencional, por el genio versátil del maestro con lastre del realismo del norte. La niebla y las montañas entre acantilados están cargadas de ensueños y recuerdos de los viajes al sur a través de los Alpes y los Apeninos. Nada de esto vio nunca Martín de Vos en los Países Bajos. Esta comprensión de la naturaleza con sus insondables perspectivas, prueba la capacidad de Martín de Vos como pintor de paisajes, que le hubiera permitido competir con Pedro Brueghel el Viejo, su compañero en la aventura italiana.

El concierto de las musas y Apolo del museo de Modena de Tintoretto (con quien tuvo contacto en Venecia) pudo ser una fuente de inspiración para la obra que tratamos, pero tampoco descartamos recuerdos de las Sibilas de la Sixtina de Miguel Angel, al confrontar dos grupos de mujeres como hizo Velázquez en la Hilanderas un siglo después. Todo parte de la fiel simetría y equilibrio de las masas. Tampoco olvidamos el grabado de Goltzius de Apolo y las musas, según dibujo de Frans Floris que estimamos de interés reproducir [Fig.2]. La amplitud de las formas y su concentración, y algunas actitudes nos mueve a ver aquí la fuente directa, aunque sustituyendo Apolo a la diosa. Frans Floris fue maestro aficionado a la música y Martin de Vos fue su discípulo, aunque trató con mayor variedad cromática sus pinturas y más contacto con la naturaleza. El grabado es interesante por registrar el nombre de las musas y los instrumentos en la cartela del ángulo alto a la izquierda. La identificación de las musas no es importante, puesto que la fantasía de los artistas domina sobre la realidad histórica impidiendo todo riguroso análisis ${ }^{5}$.

Martin de Vos se valió de la Teogonía de Hesiodo para fijar el número de las diosas que son nueve en su iconología. Las hijas de Mnemosina cantan en el Olimpo las maravillas de los dioses y conocen lo presente, lo pasado y venidero y nos divierten en sus conciertos celestiales ${ }^{6}$. Ellas personifican las virtudes

\footnotetext{
${ }^{4}$ CARel VAn MANDer, Le Livre des peintres.Vie des peintres flamands, hollandais et allemands (1604), ed. Henry Hymans, 1885, Tomo II, p.91

5 Guy de Tervarent, Attributs et Symboles dans l'art profane, Geneve 1958, 279 a 281

6 I. Aghion, C. Barbillon, F. Lissarrague, Guía iconográfica de los Héroes y dioses de la Antigüedad, Madrid, 1997, p.242.
} 


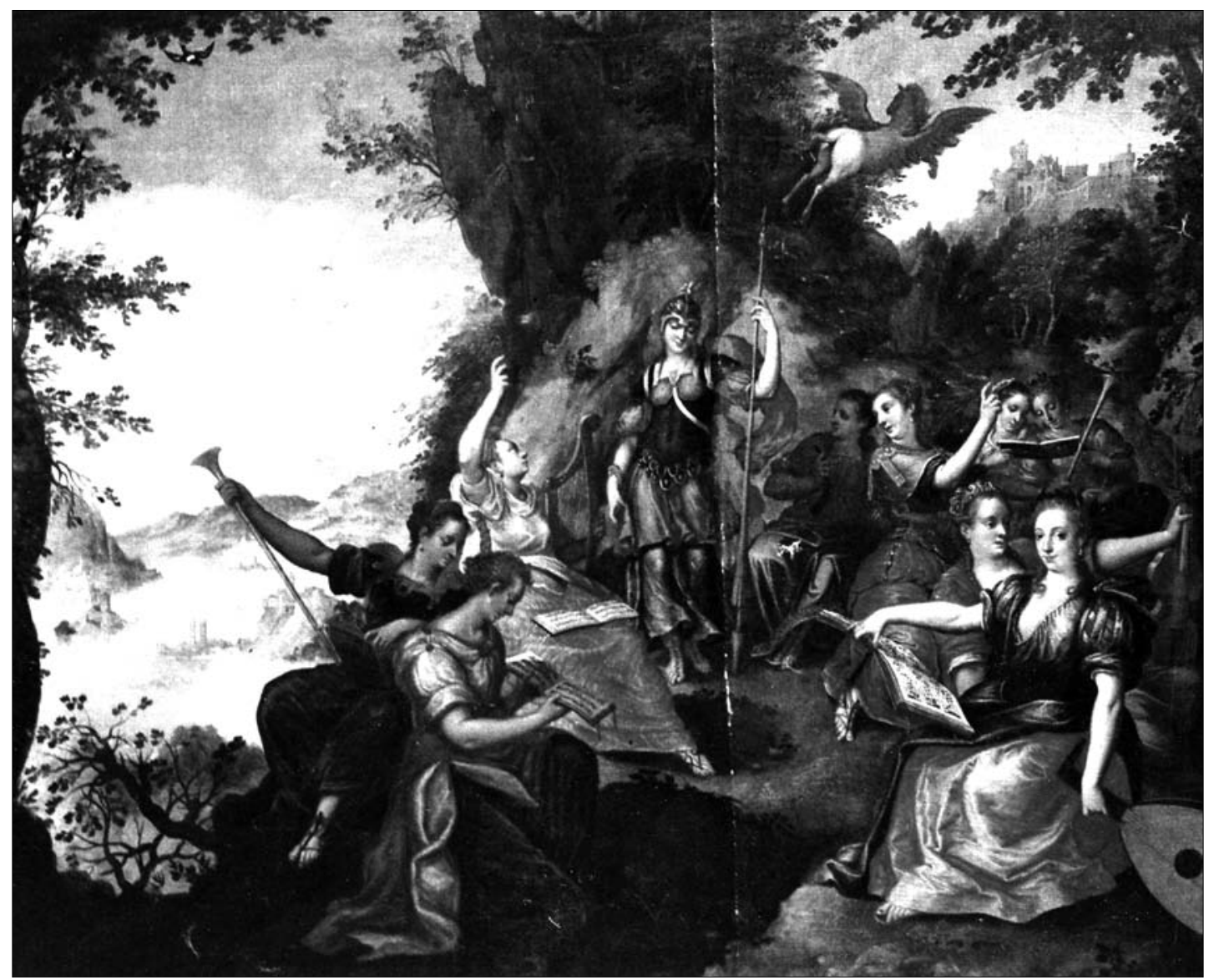

Fig. 1. Martín de Vos, Minerva y las Musas en el Helicón, colección privada.

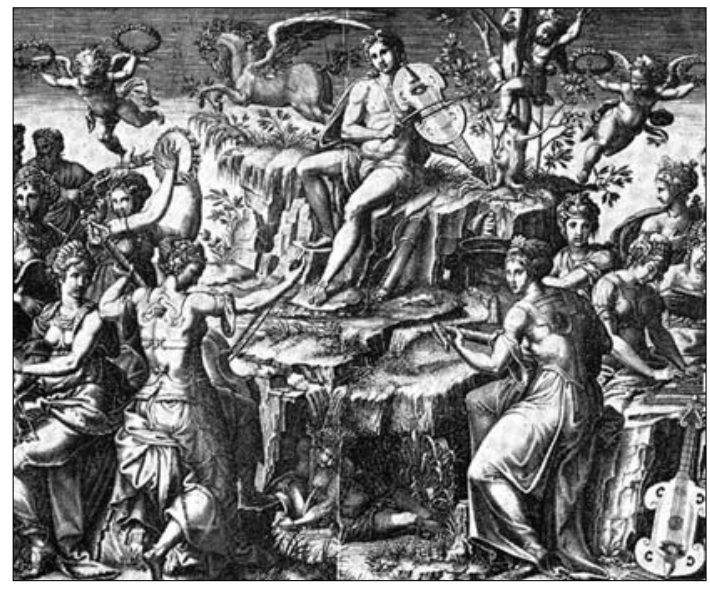

Fig. 2. Frans Floris, Apolo y las Musas, grabado por Goltzius.

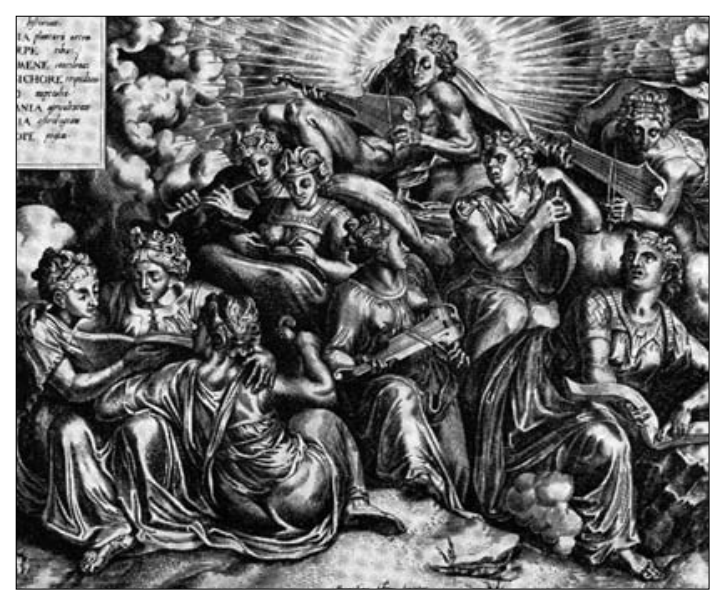

Fig. 3. Luca Penni, Concierto de Musas, grabado por Giorgio Ghizi. 
invocadas por los poetas y pintores. Son jóvenes bellas y modestas. Las partituras e instrumentos musicales son los típicos de la época: laud, violín, trompeta, arpa, cuerno y partituras. Es un rico material útil para los musicólogos del siglo XVI.

Ellas, las musas, son Clio, Euterpe, Calia, Merpómene, Tersícole, Polimnia, Urania y Calíope, todas y Minerva a los pies del Helicón fieles a la narración de Ovidio del libro V de sus Metamorfosis. Es el homenaje más sublime de la antigüedad a la música: "Hasta aquí la Tritonia acompaña a su hermano, nacido de la lluvia de oro. Luego se rodea de una nube hueca abandona Cefiros, dejando a su derecha Citnos y Gíaros, y por el camino más corto, por encima del mar, se dirigió a Tebas y al virginal Helicón. Cuando alcanzó este monte, se poso y habló así a las doctas hermanas: "Ha llegado a mis oídos la fama de una nueva fuente, que el duro casco del alado hijo de Medusa hizo brotar. Esta fuente es motivo de mi viaje. He querido contemplar ese prodigio. Lo ví nacer de la sangre de su madre." Urania le responde: "sea cual sea tu motivo, diosa, para visitar esta morada, es muy grato a nuestro corazón. Pues bien, esa fama es verídica; es Pegaso el origen de esta fuente. "Luego condujo a Palas hasta el sagrado venero. Ella, tras admirar aquellas aguas nacidas a coces, pasea su mirada por la espesura de la añosa selva por la cueva y por el prado salpicado de flores , y llama felices, tanto por su quehacer como por su morada, a las hijas de Mnemosine. Una de las hermanas le dice así: "Tritonia, habrás formado parte de nuestro coro, si tu vida no te hubiera llevado a mayores empresas, pues si tu amas nuestras artes y nuestros parajes"7

Insistiendo en las fuentes de inspiración, es posible reconocer la más directa en un grabado de Giorgio Ghizi de Apolo y las musas de Luca Penny [Fig.3]. Apolo sustituye a Minerva, pero la cohesión de los grupos es similar al lienzo de Martín de Vos. Un equilibrio que van Puyvelde estima característica del pintor. Es típico el brillo de las telas y los vestidos con ricas vibraciones y tonalidades. Repite el rojo saturado, el amarillo carmesí, verde vivo y rosa tierno en las carnaciones. Toda una gama cromática que delata su aprendizaje con los maestros venecianos.

El tema elegido por Martín de Vos es un testimonial documento del gusto de la alta burguesía del norte entre 1550 y 1650, y evidente enclave en las ideas estéticas del Renacimiento. Esta representación monumental en lienzo fue copiada frecuentemente en las cubiertas de los clavecines y gabinetes de pintura ${ }^{8}$. En uno, un modesto discípulo de Martín de Vos reproduce con exactitud el citado de Apolo y las Musas de Palermo. Martín de Vos contribuyó al prestigio de la música instrumental en Amberes. La música era para aquella refinada sociedad un regalo de los dioses con el patrocinio de Minerva y Apolo.

Esta composición la divulgan sus discípulos Henry de Clerk y H. van Balen entrado el siglo XVII, pero la distribución de las masas es mas densa, armónica y grave en Martín de Vos.

La localización de la pintura de Martín de Vos en España no es novedad, obras suyas encargaron los archiduques y la nobleza española para las iglesias de los Paises Bajos, terriblemente saqueadas por el furor iconoclasta. Proyectó los Arcos de triunfo a la entrada del Archiduque Ernesto ${ }^{9}$, y en noticia citada por Lomazzo $^{10}$, nos informa que Felipe II le encargó cuatro pinturas que desgraciadamente no han llegado a nosotros. Para Van Mander, su amigo y contemporáneo, fue uno de "los [pintores] que contribuyó al prestigio de Amberes en la pintura"11. Don Diego Angulo nos avisó antes que otro estudioso, de la presencia de

7 Ovidio, Metamórfosis, ed. Alianza Editorial, 2000, Libro V, p. 178.

8 A. P. DE Merimonde "Les Concerts des Muses chez les Maitres du Nord", Gazzette des Beaux-Arts, 1964, p.129

${ }^{9}$ Van Mander, op.cit., Tomo II, p.94; A. Doutrepont, "Martín de Vos et l'entrée triomphale de l'archiduc Ernest d'Autrihe", Buletin de l'Institut historique belge de Rome, 18, 1937, p. 125.

10 Lamazzo, Idea del Templo Della Pintura, 1590, p.162: "Il quale oltre molte altre opere portate quá é lá peril mondo á diversi Principi ne há mandato quattro al Catolico Filippo Ré di Spagna, uno di Christo all horto cò ì discepoli allumato dáll Angelo. L'altro dell Angelo con Lotto, e le figlie che fuggono dalle arse citta, il terzo di Santa Maria co 1 figlio, con San Gioseffo che passa sopra una nave per venire in porto,e l'ultimo d'una Venere ignuda, sopra un letto che ride vedendosi comparir avanti un satiro con Mopti tesoro a donaldi per acquistar la gratia di lei. E quivi è anco un Cupido che piange scorgendo il brutto desiderio di questo e la lascivia grande di quella, che per acquisitare tesoro a ciascun si sottopone" ( Cit VAN MANDER, op.cit., 1885, Tomo II, p.94, nota 1).

11 VAN MANDER, op.cit. 1885, Tomo II, p. 92 
obras suyas en España ${ }^{12}$; De Mesa y Gisbert ${ }^{13}$ de envíos a las Indias a través de Sevilla, la más próspera ciudad del renacimiento donde no faltaban obras suyas ${ }^{14}$

Además de las conocidas en la Real Academia de Bellas Artes ${ }^{15}$, Museo de Bilbao ${ }^{16}$ y tres de los cuatro Elementos en el Museo del Prado, desplazadas el siglo pasado a los depósitos del Consejo de Estado por cuestionar su interés $^{17}$. Algunas pinturas más existen en colecciones privadas ${ }^{18}$. Lo localizado en el Museo del Prado (en estos últimos años) responde al justificado pesimismo del profesor Hymans a fines del siglo XIX, lamentando la falta de obras del pintor en las colecciones del Museo, cuando por fortuna existían en el anonimato por aquellos años.

MATÍAs DíAz PADRÓN

12 “Martín de Vos en España y Méjico”. Miscellanea prof. Dr. D. Rogeen, 1953, p. 9

13 "MARTín DE Vos, en América" Anales del Instituto de Arte Americano e Investigaciones Estéticas, Buenos Aires 1970, p.36; F. de la Maza, El pintor Martín de Vos, en México, 1971.

14 J. Hernández DíAZ, Sevilla, Museo Provincial de Bellas Artes, 1967, p.42, no 2.

15 J. GeSTOSO Y PÉREZ, Notice historique et bibliographique des principaux artistas flamands quitravaillèrent à Seville después le XVIe siècle jusqu'a la fin du XVIIIe. Les arts anciens de Flandre, 4, 1910, p.186; F. Labrada, Catálogo de los Pintores, Madrid. Real Academia de Bellas Artes de San Fernando, 1965, 86, $\mathrm{n}^{\circ}$ C. 15

16 C. DE Lasterra, Museo de Bellas Artes de Bilbao. 1967, p.127.

17 M. Díaz Padrón, "Tres lienzos de Martín de Vos, identificados en el Consejo de Estado y en la colección Osuna" Boletín del Museo del Prado, tomo III, n 7, 1982, pp.3. Uno se encuentra en la colección ducal de Osuna. El Fuego posiblemente sea el que se encuentra hoy sin referencia alguna y en lamentable estado de conservación, con atribución genérica a escuela flamenca, inventario de $1857 \mathrm{n}^{\circ} 2275$, corresponde al actual n 3563 del Museo del Prado. Puede tratarse del que falta, con proyecto de su estudio más detenido.

18 M. Díaz Padrón, "Tres lienzos de Martín de Vos, identificados en el Consejo de Estado y en la colección Osuna" Boletín del Museo del Prado, tomo III, n 7, 1982, p 3. Uno se encuentra en la colección ducal de Osuna. El Fuego posiblemente sea el que se encuentra hoy sin referencia alguna y en lamentable estado de conservación, con atribución genérica a escuela flamenca, inventario de $1857 \mathrm{n}^{\circ} 2275$, corresponde al actual $\mathrm{n}^{\circ} 3563$ del Museo del Prado. Puede tratarse del que falta, con proyecto de su estudio más detenido.

19 Margarita Estella, "Algunas obras de Martín de Vos en España” Archivo Español de Arte, 45, 1972, p. 66; M. Díaz Padrón, "Miscelanea de pintura flamenca", Archivo Español de Arte, 1984, p. 337, fig. 22. 